\title{
CO-BRANDING PARTNER SELECTION: THE IMPORTANCE OF BELIEF REVISION
}

\author{
Chia-Lin LEE ${ }^{1}$, Reinhold DECKER ${ }^{2}$ \\ ${ }^{1}$ Department of Business Administration, National Chengchi University, No.64, Sec. 2, \\ Zhi Nan Rd., Wenshan District, Taipei City 11605, Taiwan \\ ${ }^{2}$ Department of Business Administration and Economics, Bielefeld University, \\ Universitätsstraße 25, 33615, Bielefeld, Germany \\ E-mails: 1clee@nccu.edu.tw (corresponding author); ${ }^{2}$ rdecker@uni-bielefeld.de
}

Received 13 September 2015; accepted 01 June 2016

\begin{abstract}
This paper applies the stereotype change theory to help bridge a major literature gap on co-branding partner selection: why both identical and highly different brand pairs often fail. We argue that, given that a primary goal of establishing a co-branding alliance is to positively revise consumers' beliefs about important attributes of the allying brands, the case of no belief-revision can lead to a failure of the alliance. We show that both an identical and a highly incongruent partnership in terms of attribute-level difference can fail due to the lack of belief-revision. We report that a moderately incongruent brand pair is a promising decision on co-branding partner selection. In doing so, our research contributes to the explanation of why the two "extreme" types of co-branding alliances may fail from the perspective of consumer evaluation. For brand managers, we offer a normative guideline for co-branding partner selection.
\end{abstract}

Keywords: belief-revision, co-branding, partner selection, stereotype change, bookkeeping, sub-typing.

JEL Classification: M31.

\section{Introduction}

Co-branding, an entrepreneurial partnership in which two brands are presented together on a product or service, has been a popular topic in marketing research for over two decades, and is gaining increasing importance among practitioners (Lanseng, Olsen 2012). There are many real world examples of successfully co-branded products, but there are also numerous co-branding failures (e.g., the success of Nike-Apple sport kits, and the failure of BenQ-Siemens mobiles). However, academic research on co-branding success is rather scarce (Hadjicharalambous 2006), and marketing researchers have not yet identified clear factors, guidelines, or tools for selecting an ideal co-branding partner, the most critical issue to co-branding success (Cummings, Holmberg 2012).

Focusing on co-branding partner selection, Walchli (2007) reported that, under a highinvolvement condition, the "moderately incongruent" co-brand receives the most posi- 
tive attitudinal evaluation. Hence, from the attitudinal favourability perspective, we argue that the other two co-branding alliances, "identical" and "highly incongruent" pairs, turn out to be failures. Extant research (e.g., Park et al. 1996; Geylani et al. 2008) also found that the "moderately incongruent" pair may prompt consumers to revise their beliefs about the important attributes of the allying brands ${ }^{1}$. In the following we call this process "Belief-Revision" (BR), whereby after the release of a co-branded product, consumers tend to develop the positive BR (i.e., belief enhancement; Loken, Roedder John 1993) for each of the allying brands.

In fact, consumers' positive BR is a key factor for building and sustaining a successful co-branding partnership for two reasons. First, similar to the purpose of brand extension, for each brand partner, an important goal of co-branding is to strengthen existing attribute-beliefs about the brands and the associated brand images (Besharat, Langan 2014). Secondly, the positive BR of one brand in a co-branding alliance often results from the other's positive attribute performance (Hillyer, Tikoo 1995; Ambroise et al. 2014). In the ideal case, the positive BR occurs for both brands if each brand excels in different attributes (Park et al. 1996). Thus, the positive BR mutually benefits brand partners; the larger the magnitude of BR, the better for each brand.

Given that consumers' BR is an important motive for alliance formation, we argue that an alliance resulting in no BR can lead to a co-branding failure. From this perspective, we once again turn to Walchli's (2007) findings to explain why the two "extreme" alliance types - "identical" and "highly incongruent" pairs - tend to fail. A better understanding of this unresolved problem is also crucial for marketers seeking successful brand partners. Wrong decisions regarding partner selection not only result in a failure of the co-branded product or service, but could also weaken the equities of the allying brands (Hadjicharalambous 2013).

Therefore, we explore why the two "extreme" alliances may fail by employing the stereotype change theory (Weber, Crocker 1983), a well-accepted theory that explains consumers' cognitive process in BR (e.g., Sheinin 2000; Desai, Keller 2002). To the best of our knowledge, we are the first to apply the two competing models of stereotype change (i.e., the "book-keeping" and the "sub-typing" model) to explain why the two "extreme" cases can fail. In doing so, we also contribute to the growing literature on the key topic of belief enhancement and dilution (e.g., Luo et al. 2010). The remainder of this paper is organized as follows. Section 1 reviews the relevant literature. Section 2 presents three research propositions and the model, followed by the mathematical proofs of the propositions in Section 3. Section 4 finally shows the empirical results, ending with the conclusions.

\footnotetext{
${ }^{1}$ We use the terms "allying brands" and "partnering brands" interchangeably to represent the partners (e.g., Sony and Ericsson) participating in a co-branding partnership (e.g., Sony-Ericsson).
} 


\section{Literature review}

\subsection{Consumer-based evaluations for partner selection}

A well-suited brand partner may significantly contribute to co-branding success via synergistic value (Rao, Ruekert 1994) as well as an increased value for an individual partner (see, e.g., Cao, Sorescu 2013). A comprehensive literature review reveals that marketing scholars have successfully used Consumer-Based Brand Equity (CBBE) as a measure to evaluate how a low- or a high-equity brand chooses its partner (e.g., Washburn et al. 2000; Besharat 2010; Kalafatis et al. 2012). The CBBE measures the psychological brand value in terms of consumers' attitudes, brand associations, and brand images (Keller 1993). Therefore, in the following, we employ a core unit of CBBE (Na et al. 1999), namely the consumers' perceived attribute-level (i.e., attribute-belief), as the main measure of the partner selection decision. Attribute-belief is an important component of CBBE (Winchester, Romaniuk 2008), and is connected with the brand image and associations, the key dimensions of CBBE (Keller 1993). Prior research has already unveiled how each brand partner can achieve a positive change-in-belief rating for important attributes (i.e., positive BR), and how a positive BR can lead to a positive change in brand images and associations (e.g., Park et al. 1996; Hillyer, Tikoo 1995; James 2005; Geylani et al. 2008; Van der Lans et al. 2014). However, an explicit use of attribute-belief for evaluating co-branding partner selection has not yet been reported in the relevant literature. By closing this gap, we contribute to a better understanding of the underlying reasons behind the CBBE changes (cf. Pappu et al. 2005).

However, a crucial problem of the CBBE measure is the inevitable subjectivity of respondents (Davcik et al. 2015). A contemporary way of solving this problem is to use a broader construct than CBBE (Davcik et al. 2015). For instance, one might combine CBBE with the Brand Value Co-Creation model (BVCC) (e.g., Merz et al. 2009), which is rooted in both the brand community theory (e.g., Muniz Jr. et al. 2001) and the service brand concept (e.g., Brodie et al. 2006). The use of BVCC can enhance the dynamic and interrelated influences of various stakeholders (e.g., employees and brand communities) on brand value. However, we use only the CBBE measure for three reasons. First, it is difficult to integrate both constructs in one study, because BVCC and $\mathrm{CBBE}$ are grounded in different theories. Furthermore, by using an integrated measure with BVCC, we can easily lose our focus on the consumer perspective, which is the mainstream view in co-branding research. Thirdly, this paper explores the static changes (i.e., pre-post differences) in consumer evaluations rather than the dynamic influences of stakeholders.

\subsection{A major cause of belief revision: between-partner fit}

Attribute-belief is also considered an important element of consumers' attitudinal evaluation (e.g., Fishbein, Ajzen 1975; Lichtenthal, Goodwin 2006). Research in consumer psychology, among others, explores how one brand achieves a favorable attitudinal evaluation of a co-brand by selecting the most appropriate partner (Leuthesser et al. 2003). In other words, from an attitudinal viewpoint, the level of perceived between- 
partner fit is a crucial factor of co-branding success. For example, Park et al. (1996) showed that attribute-complementarity, that is, a good product-fit (e.g., one brand has an exceptional flavor but is high in calories, and the other has opposite features), creates a good attribute profile that prompts consumers to form a more favorable attitude toward this type of co-branding alliance than others. Simonin and Ruth (1998) reported that a more favorable attitude toward the co-brand occurs only when the alliance exhibits a good brand-fit. Cao and Sorescu (2013), Lee et al. (2013), and Van der Lans et al. (2014) also postulated a good brand-fit to be a key factor of co-branding success. Based on the congruence theory (Meyers-Levy, Tybout 1989), Walchli (2007) analyzed how between-partner congruency affects consumer evaluations of the co-brand. The author reported that:

(1) under a high-involvement processing condition, a brand alliance with a moderate difference (e.g., Business Week and The Wall Street Journal) leads to a more favorable evaluation, and

(2) a complementary but highly-incongruent brand partnership (e.g., Business Week and People) receives a negative evaluation, and

(3) consumers usually regard an identical brand pair (e.g., Business Week and Fortune) as a redundant and non-complementary pair.

Walchli (2007) concluded that the perceived incongruence between two allying brands should not exceed a certain level. In sum, the above-mentioned studies explain the influences of different between-partner fits on attitudinal changes. As attribute-belief is considered a core unit of consumers' attitudinal evaluation, we argue that BR is also crucial to a firm's partner selection decision.

To the best of our knowledge, Hillyer and Tikoo (1995) is a seminal piece in explaining the impact of between-partner fit on changes in the attribute-belief level (i.e., BR). They found that consumers' beliefs regarding the perceived attribute-level of the secondary brand (e.g., the beliefs about the attribute-level of the attribute, "entertainment", with Ericsson in the Sony-Ericsson alliance) may be influenced by the beliefs of the "first" brand (e.g., the beliefs about the attribute-level of "entertainment" with Sony) ${ }^{2}$. Under the attribute-complementarity setting, Geylani et al. (2008) used a connectionist model of brand associations (Janiszewski, van Osselaer 2000) to formulate the underlying process of BR. They found that consumers' attribute uncertainties about one brand may be transferred to the other brand through a co-branding alliance. Additionally, they reported that the difference between the partnering brands in terms of perceived attribute performance levels (i.e., attribute-belief) decreases through an alliance. Therefore, it may be better for one brand to partner with a brand that is perceived as having only moderately higher performance. Following Geylani et al. (2008), Lee and Decker (2009) confirmed the success of a moderately different pair. In summary, current findings on BR reveal a significant gap because they do not explain why the two "extreme" pairs may fail.

\footnotetext{
2 The use of the terms "attribute" and "attribute-level" in this research is similar to the use in the conjoint analysis.
} 


\section{Propositions and model setting}

Next, we develop three propositions and a mathematical model to gain a better understanding of partner selection decisions. Moorthy (1993) postulated that marketing researchers can use a theoretical and mathematical modeling approach to help managers identify key decision variables first, and then take a more general perspective when the decision-making environment changes (e.g., Miklos-Thal 2012). Therefore, we build our considerations on theory-driven propositions, and then employ a mathematical approach for proving them. We use the two models of stereotype change, namely the "book-keeping" (e.g., Sheinin 2000) and the "sub-typing" model (e.g., Vaidyanathan, Aggarwal 2000), to show the absence of BR can lead to a failure in the above-mentioned "extreme" pairs, because researchers have successfully utilized these two models to explore the cognitive processes of BR in branding research (e.g., Loken, Roedder John 1993; Desai, Keller 2002).

\subsection{Propositions}

The book-keeping model assumes that, in the co-branding context, the perceived "new" attribute information concerning the co-brand causes the consumers to modify previous attribute-beliefs regarding the allying brands, and the magnitude of BR is determined by the amount of disconfirming attribute information. Accordingly, the book-keeping model suggests that the amount of incongruent attribute information positively influences the magnitude of BR. The resulting proposition reads as follows:

Proposition 1 (The case of identical brands)

From the consumer evaluation perspective, under the book-keeping model, a brand benefits by not forming an alliance with an identical brand (partner) in terms of attributelevel difference.

Note that a completely "identical" pair of brands is difficult to find in reality because of the obvious drawbacks from the lack of attribute-complementarity (Park et al. 1996). However, the identical case remains important for further and advanced discussions (e.g., Van der Lans et al. 2014). According to Walchli (2007), the logic behind Prop. 1 is that consumers consider such a brand pair redundant and thus are not interested in it. As a result, consumers do not update their attribute beliefs. In our illustration, we argue that the partnering brands have no incentive to form an alliance since it would not result in the significant positive BR. This proposition motivates why an identical alliance can lead to a failure. The hypothetical Business Week and Fortune co-branded magazine (both featuring the attribute of timely business news) and the hypothetical Asus-Acer co-branded laptop (both featuring the attribute of free-from-defects) are typical examples of this scenario.

In contrast to the book-keeping model, the sub-typing model assumes that consumers' perceived new attribute information from the co-brand does not always change their established attribute-beliefs about the allying brands. Here, the amount of incongru- 
ent attribute information may have a negative impact on BR. We specify the second proposition as follows:

Proposition 2 (The case of highly incongruent brands)

From the consumer evaluation perspective, when sub-typing is in effect, it is better for a brand not to ally with a complementary brand that exhibits a huge attribute-level difference.

According to Walchli (2007), in this scenario, consumers may become frustrated when resolving the high discrepancy between the two brands, and will thus have no inclination to revise their attribute-beliefs about the allying brands. As a result, the partnering brands do not gain from this co-branding partnership. Hypothetical examples corresponding to this scenario could be the Filofax-Calvin Klein personal organizer (featuring a significant difference regarding the attribute "well-organized"), the Business Week and People co-branded magazine (Walchli 2007), or the Evian-Vanish stain remover (featuring a significant incongruence regarding the attributes "purity" and "cleanness"). ${ }^{3}$

Proposition 3 (The case of moderately incongruent brands)

From the consumer evaluation perspective, when either the sub-typing or the bookkeeping model is in effect, a "moderately different" brand partner in terms of attributelevel difference would be the optimal choice.

According to Geylani et al. (2008), the "moderately incongruent" pair is considered a complementary set of attributes-levels. In this case, consumers would tend to process BR on the important attributes of the allying brands. The former co-brand, Sony-Ericsson, exemplifies how a positive BR may occur on the key attributes of each brand partner (e.g., the belief regarding the "entertainment" attribute of Ericsson may be enhanced after the co-branding alliance). Therefore, the two brands are motivated to partner with each other. This proposition, together with the above two, can help brand managers get a more holistic picture of the partner selection decision.

\subsection{Model setting}

In this subsection, we introduce a mathematical model to illustrate the process underlying BR in co-branding. Our model is motivated from Geylani et al. (2008). In contrast to their model, our work aims to explain why the two "extreme" brand pairs can fail by utilizing the stereotype change theory. ${ }^{4}$ Additionally, our mathematical notations present an intuitive graphical illustration of the BR process. In doing so, our model helps marketing managers, who are interested in co-branding activities, fully understand how the changes in attribute-belief affect consumers' brand-choice decisions, particularly if the importance weight of the concerned attribute is high (cf. expectancy-value model,

\footnotetext{
${ }^{3}$ This example is motivated from Keller (2007). The author mentioned that Evian (natural spring water) and Johnson \& Johnson (cleaning products) may dilute the associations and consumers' beliefs about the "purity" of Evian.

${ }^{4}$ The mathematical setting of Geylani et al. (2008) focused mainly on how the attribute uncertainties of one brand could be transferred to the other one. However, to the best of our knowledge, they did not apply a theory for the partner selection decision.
} 
e.g., Bass, Talarzyk 1972). The variables and parameters used in the model are defined as follows:

$i$ - index for time points; $i=1,2$;

$D-D \in\{L, C\}=$ a set of brands;

$U-U \in\{x, y\}=$ a set of product-related attributes;

$P_{D(i)}$ - the product released by brand $D$ at time $i$;

$P_{L C}$ - the product released by the co-brand;

$\Phi_{D(i)}$ - consumers' preference score for brand $D$ at time $i$;

$\beta_{D(i)}^{U}$ - consumers' belief about attribute $U$ of brand $D$ at time $i$;

$\beta_{L C}^{U}$ - consumers' belief about attribute $U$ of the co-brand;

$d^{U}$ - initial (i.e., $i=1$ ) attribute-level difference of attribute $U$;

$w^{U}$ - consumers' relative weight of importance of attribute $U$;

$\lambda_{D}^{U}$ - relative contributing weight of attribute $U$ of brand $D$;

$r_{D}^{U}$ - updating weight of attribute $U$ of brand $D$;

$\Omega$ - a set of the consumer's attribute-beliefs about brand $C$.

We start from the assumption that the two brands, $L$ and $C$, are potential partners in a co-branding alliance. Furthermore, we assume that these brands are differentiated by consumers' different attribute-beliefs. At time $i=1$, each brand produces its own branded product, $P_{D(i)}$. At $i=2$, the two brands have already cooperated with each other, and the co-branded product $P_{L C}$ has already been released during the intermediate period. We further suppose that the considered market contains all the potential buyers of brands $L$ and $C$ (e.g., Venkatesh et al. 2000), and all these consumers have noticed the co-branded product during the intermediate period. Finally, we assume that consumers use two product-related attributes, $x$ and $y$, to evaluate brands $L$ and $C$.

Starting from this setting, we use the expectancy-value model (Bass, Talarzyk 1972) to formulate consumer preferences. The preferences at time $i$ are formulated as a relative score composed of consumers' relative weights of attribute importance $w^{U}>0$ and the attribute-beliefs $\beta_{D(i)}^{U}>0$. Hence, the preference score of each brand, $\Phi_{D(i)}$, is expressed as:

$$
\Phi_{D(i)}=\sum_{U} w^{U} \times \beta_{D(i)}^{U}
$$

Next, we will set up a geometric space that further details the BR process. This setting is consistent with a series of two-dimensional differentiation models (e.g., Lauga, Ofek 2011). We start with the specification of the consumer's initial (at $i=1$ ) attribute-beliefs about the partnering brands (hereafter called pre-alliance beliefs). First, we establish a two-dimensional space (see Fig. 1), where the boundary of each attribute is given by the interval $[0,100]$. We then plot attribute-beliefs at different time points. For example, at $i=1$, if one consumer perceives brand $L$ on level 60 for attribute $x$ and on level 40 for $y$, then this consumer has a combined attribute-level pair of $L:\left(\beta_{L(1)}^{x}, \beta_{L(1)}^{y}\right)=(60,40)$. 
We further assume that the consumer perceives brand $L(C)$ to perform well on attribute $x(y)$, but not on $y(x)$ at $i=1$. (i.e., attribute-complementarity; Park et al. 1996). Therefore, $\beta_{L(1)}^{x} \geq \beta_{L(1)}^{y}$ holds true, and the consumer's attribute-beliefs of $L$ are located in the lower triangle $B V Z$ of Figure 2. Besides, $\beta_{C(1)}^{y} \geq \beta_{C(1)}^{x}$ holds true, and the consumer's attribute-beliefs of brand $C$ appear in the upper triangle ETQ in Figure 3.

The consumer's attribute-beliefs of $C$ can be represented by the following set $\Omega$ :

$$
\Omega=\left\{\left(\beta_{C(1)}^{x}, \beta_{C(1)}^{\mathrm{y}}\right) \in \mathrm{R}^{+} \mid \beta_{C(1)}^{\mathrm{y}} \geq \beta_{C(1)}^{\mathrm{x}} ; \beta_{C(1)}^{\mathrm{x}} \leq \beta_{L(1)}^{\mathrm{x}} ; \beta_{C(1)}^{\mathrm{y}} \geq \beta_{L(1)}^{\mathrm{y}}\right\} .
$$

In Equation (2), the first inequality, $\beta_{C(1)}^{y} \geq \beta_{C(1)}^{x}$, indicates that the consumer knows that $C$ performs well on $y$ but not on $x$. The second inequality, $\beta_{C(1)}^{x} \leq \beta_{L(1)}^{x}$, denotes that $L$ is known for performing better than $C$ on $x$. Finally, the third inequality, $\beta_{C(1)}^{y} \geq \beta_{L(1)}^{y}$, indicates that $C$ performs better than $L$ on $y$. The set $\Omega$ is plotted in Figure 4, represented by the upper pentagon IJKMO.

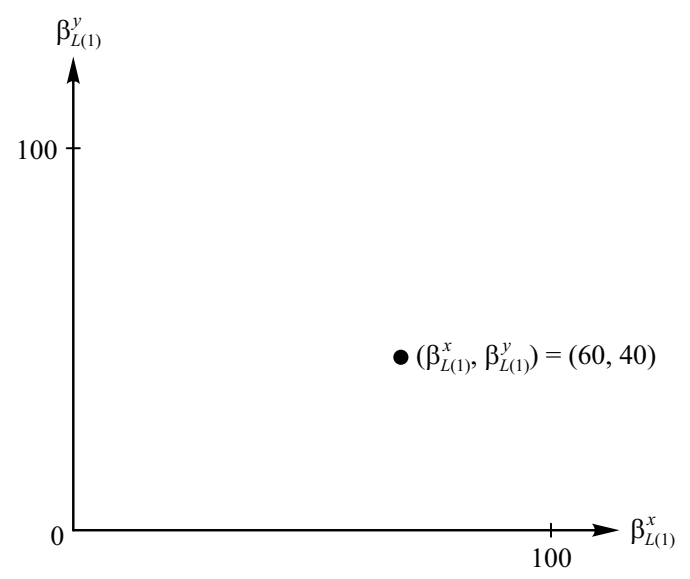

Fig. 1. The two-dimensional space of attribute-beliefs

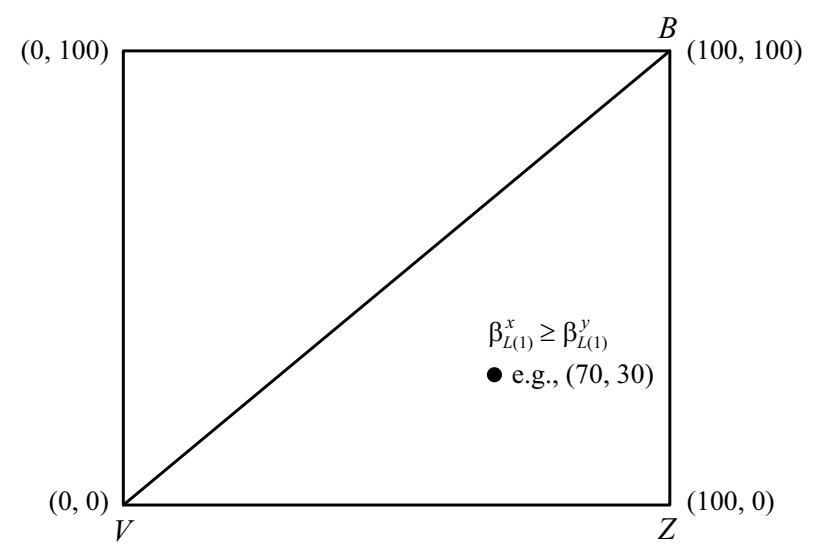

Fig. 2. The consumer's pre-alliance beliefs about $L$ 


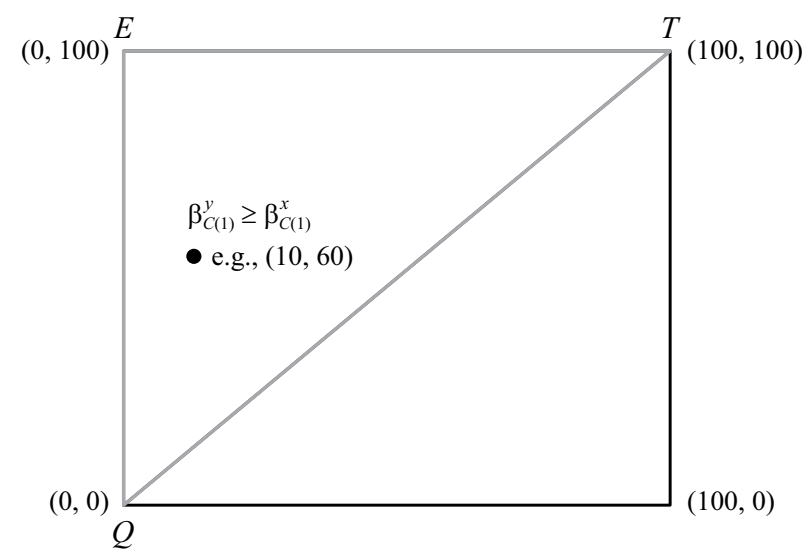

Fig. 3. The consumer's pre-alliance beliefs about $C$

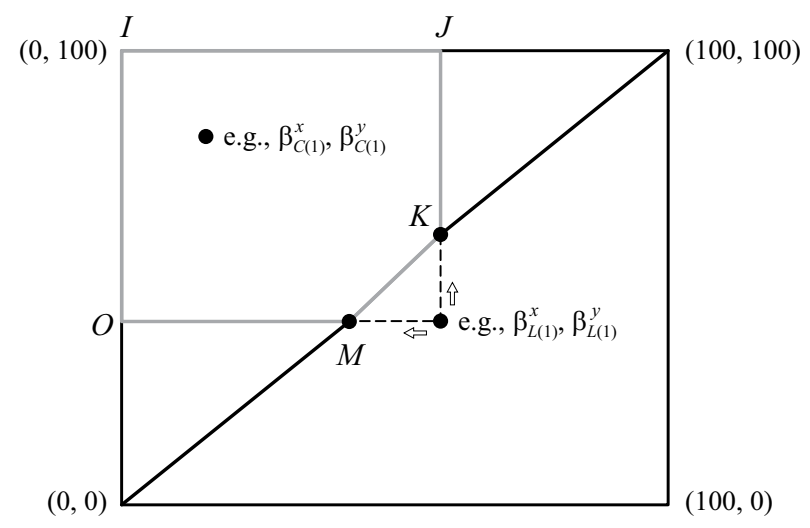

Fig. 4. The consumer's pre-alliance beliefs about $L$ and $C$

We use $d^{U}$ to denote the consumer's initial attribute-level difference of attribute $U$ between $L$ and $C$ at $i=1$ and define:

$$
d^{U}=\left|\beta_{L(1)}^{U}-\beta_{C(1)}^{U}\right|, \text { where } U \in\{x, y\} .
$$

So, $d^{U}$ is a continuous function of $\beta_{D(1)}^{U}$. We further assume that the difference is the same for the two attributes, i.e. $d=d^{U}$. This assumption is motivated by Geylani et al. (2008).

Now, we move to the consumer's beliefs about the co-branded product (hereafter called co-branding beliefs), and the post-alliance (at $i=2$ ) beliefs about the allying brands (hereafter referred to as post-alliance beliefs). Again, as inspired by Geylani et al. (2008), we formulate co-branding beliefs and post-alliance beliefs about each brand as:

$$
\beta_{L C}^{U}=\lambda_{L}^{U} \times \beta_{L(1)}^{U}+\lambda_{C}^{U} \times \beta_{C(1)}^{U}, \text { where } \lambda_{\mathrm{D}}^{\mathrm{U}} \in[0,1], \sum_{D} \lambda_{D}^{U}=1, \text { and } U \in\{x, y\},
$$


$\beta_{D(2)}^{U}=r_{D}^{U} \times \beta_{L C}^{U}+\left(1-r_{D}^{U}\right) \times \beta_{D(1)}^{U}$, where $r_{D}^{U} \in[0,1], U \in\{x, y\}$, and $D \in\{L, C\}$.

In equation (5), $r_{D}^{U}$ determines the magnitude of the consumers' BR.

\section{Proof}

By using the above specifications, Prop. 1 (Proposition 1) can be proved as follows 5 . First, we express the book-keeping model mathematically by the following equation:

$$
(\partial r U / \partial d)>0 \text {, where } U \in\{x, y\} .
$$

That is, we assume that the magnitude of the BR $\left(r^{U}\right)$ changes positively with the difference of initial attribute-level between the two brands $(d)$. We further assume that $r^{U}$ has a lower bound, 0 , and an upper bound, $l$ (i.e., $r^{U} \in[0,1]$ ). We suppose further that $d \mapsto r^{U}(d)$ is an injective function (e.g., a monotonic function) with the oneone mapping property. Then, we can construct a sequence of $d$ (represented by the set $\left.\left\{d_{1}, d_{2}, d_{3}, \ldots \ldots ..\right\}\right)$ and a sequence of $r^{U}$ (represented by the set $\left.\left\{r_{1}^{U}, r_{2}^{U}, r_{3}^{U}, \ldots \ldots.\right\}\right)$. In other words, each element of $d$ 's sequence corresponds to the same order of each element of $r^{U}$ 's sequence. Given that $r^{U}$ is strictly monotonic increasing in $d$ with the one-one mapping property, it can be observed that if $d=0$, then $r^{U}$ approaches its lower bound, 0 .

It means that the magnitude of BR is zero when the two brands are identical in terms of the attribute-level difference. In conclusion, when book-keeping is in effect, the consumer may consider an identical pair $(d=0)$ to be redundant, Thus, no BR occurs $\left(r^{U}=\right.$ 0 ) (e.g., no changes of attribute-beliefs in Figures 2 and 3). Consequently, this leads to a failure of the alliance.

We now come to the proof of Prop. 2. We formulate the sub-typing model as follows:

$$
(\partial r U / \partial d)<0, \text { where } U \in\{x, y\} .
$$

Equation (7) indicates that the magnitude of the BR changes negatively with the difference in the initial attribute-level between the two brands. We further assume that $r^{U} \in[0,1]$. Besides, we suppose $r^{U}$ to be strictly monotonic decreasing in $d$ (e.g., $r^{U}=$ $1 /(d+1))$. This formulation shows why a consumer has difficulties in resolving the high discrepancy between the allying brands. That is, in this case, $r^{U}$ will reach its lower bound 0 when $d$ approaches $+\infty$. In other words, when sub-typing is in effect, the consumer cannot resolve the large differences in the attribute-level between the two brands. Finally, no BR occurs (e.g., no changes in attribute-beliefs in Figures 2 and 3), and this alliance fails.

Note that Prop. 3 has already been proven by Geylani et al. (2008), and because the logic behind our proof would be similar to theirs, we can skip the proof here. However, different from Geylani et al. (2008), we provide this rule by applying the stereotype change theory. We argue that the "moderately apart" alliance will be accepted by consumers, who have either the book-keeping or the sub-typing mindset.

\footnotetext{
${ }^{5}$ For the sake of comprehensibility, we analyze only the BR of one brand. Thus, hereafter, we drop index $D$.
} 


\section{Empirical study}

\subsection{Setting of the study}

The empirical study in this section illustrates our theory-driven propositions in a realworld context. To align it with the context of our propositions, we have designed a survey based on a history of a hypothetical consuming experience (Geylani et al. 2008), and used two hypothetical brands of briefcases, namely $L$ and $C$. The co-branded product of this simulated alliance, the $L C$ briefcase, is the stimulus. Two attributes, style and durability ( $x$ and $y$ in the mathematical model), are assumed to be the most important attributes when consumers evaluate a briefcase (e.g., Ahluwalia, Gurhan-Canli 2000). So, each of the two brands was manipulated with two histograms showing pre-alliance durability and style perceptions. Furthermore, we assumed that durability (style) is the salient attribute of $L(C)$. We then manipulated the attribute salience in the histograms of the perceived durability and style scores rated by 100 users (Geylani et al. 2008).

To represent the identical case considered in Prop. 1, we set the perceived mean scores of durability and style of $L(C)$ to be 97 (96) and 96 (97), respectively. That is, we assumed a very small initial attribute-level difference of attribute $U$ between $L$ and $C$ (i.e., $d=1$ ). Furthermore, to represent the highly different scenario of Prop. 2, we set the perceived mean scores of durability and style of $L(C)$ to be 97 (4) and 4 (97), respectively (i.e., $d=93$ ). Finally, to represent the moderately different case of Prop. 3, we let the perceived mean scores of durability and style of $L(C)$ to be 65 (35) and 35 (65), respectively (i.e., $d=30$ ). In the following, we regard the identical case as condition 1 , the highly different case as condition 2 , and the moderately different case as condition 3 . Table 1 summarizes these conditions, and Figure 5 shows an example of the histogram manipulation for $L$ in condition 3 .

Table 1. Setting of the survey (the scores are out of 100)

\begin{tabular}{lcccc}
\hline Condition & $\begin{array}{c}\text { Perceived } \\
\text { attribute-level } \\
\text { of durability of } L\end{array}$ & $\begin{array}{c}\text { Perceived } \\
\text { attribute-level } \\
\text { of durability of } C\end{array}$ & $\begin{array}{c}\text { Perceived } \\
\text { attribute-level } \\
\text { of style of } L\end{array}$ & $\begin{array}{c}\text { Perceived } \\
\text { attribute-level } \\
\text { of style of } C\end{array}$ \\
\hline 1. Identical & 97 & 96 & 96 & 97 \\
\hline 2. Highly different & 97 & 4 & 4 & 97 \\
\hline 3. Moderately different & 65 & 35 & 35 & 65 \\
\hline
\end{tabular}

Starting from these conditions the survey was structured as follows: the histograms showing the consumption experiences were presented to the respondents; their pre-alliance beliefs about $L$ were measured by asking the following questions for both durability and style: "According to this histogram, you gave to brand $L$ 's briefcase a durability [style] score of_." (range: 0 to 100; cf. e.g., Geylani et al. 2008). The same questions were asked about brand $C$. Then, we presented an advertisement stimulus (cf. e.g., Simonin, Ruth 1998), which shows the message of the co-branding alliance (see Fig. 6). Similar to Geylani et al. (2008), we asked the respondents to complete an unrelated filler task for approximately 10 minutes in order to clear their short-term memory of pre- 


\section{(1) Manipulation of "durability" of brand $L$}

The supposed perceived durability scores of 100 users of brand L's briefcase are given below as a histogram

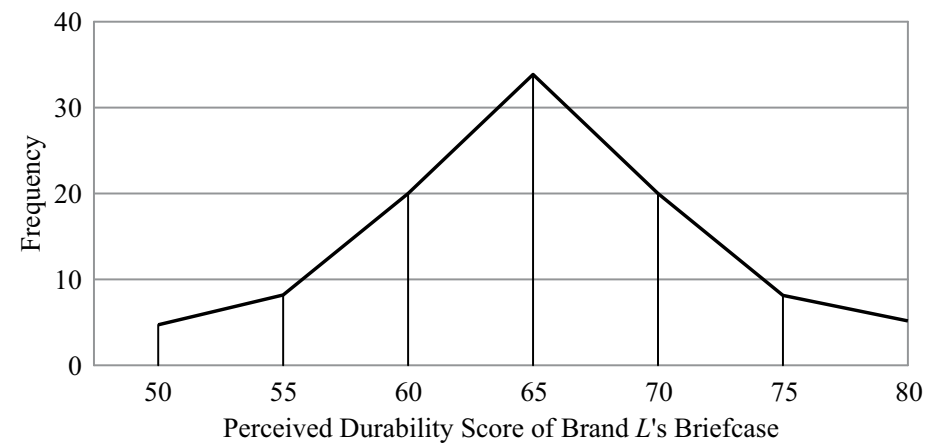

(2) Manipulation of "style" of brand $L$

The supposed perceived style scores of 100 users of brand $L$ 's briefcase are given below as a histogram

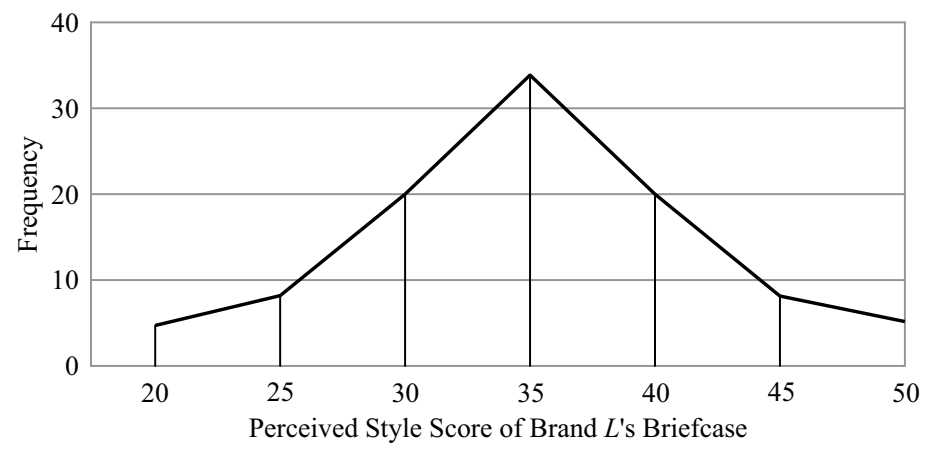

Fig. 5. Histogram manipulation of brand $L$ in condition 3

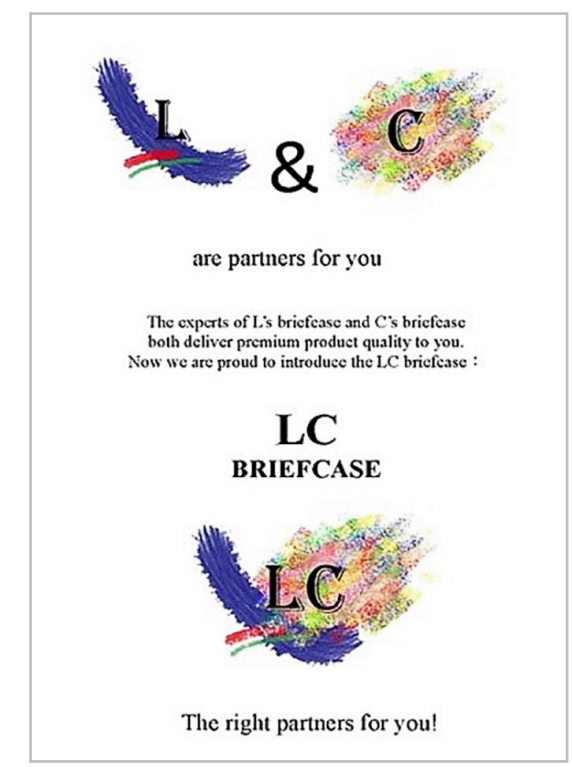

Fig. 6. The co-branding stimulus 
alliance beliefs. Finally, to measure their post-alliance beliefs about brand $L$, we asked the respondents to answer the following questions for both durability and style: "After you have seen the co-branded briefcase, you would expect the durability [style] score of $L$ 's briefcase to be_." Analogous questions were asked about brand $C .^{6}$ By obtaining answers to the above eight questions, we collected four pairs of data for measuring the magnitude of BR $\left(r_{D}^{U}\right)$. Pair 1 (2) measured the pre-post attribute-level difference on "durability" ("style") of brand $L$; pair 3 (4) measured the pre-post attribute-level difference on "durability" ("style") of brand $C$. In particular, to prevent the positive and negative changes of the attribute-level from canceling each other out, we measured the magnitude of BR by using the absolute value of the pre-post attribute-level difference for each pair.

\subsection{Hypotheses}

To show the real-world applicability of our propositions, the survey data were used to test two hypotheses. The two hypotheses were motivated by Bandy et al. (1998) and Littlewood et al. (2001). In these studies, the participants' pre-post difference, referred to as "gain scores", were measured after a medical treatment (i.e., in our case, they were measured after the presentation of the co-branding alliance). The magnitudes of pre-post changes were then compared across different groups of participants. Because BR can be a crucial motive for building a successful co-branding alliance (i.e., the larger, the better; see the Introduction section), we used this empirical approach to test whether consumers would exhibit a larger magnitude of BR in the moderately different case (Prop. 3) than in the other two cases (Prop. 1 and 2). Therefore, Hypothesis 1 (Hypothesis 2) compares the four pairs of data entered in conditions 1 (2) and 3, and it postulates that a more significant BR occurs in condition 3 than in condition 1 (2). Hypothesis 1 (H1) and Hypothesis (H2) read as follows:

H1: The mean of the pre-post attribute-level differences in condition 3 (the moderately incongruent case) is larger than that in condition 1 (the identical case).

H2: The mean of the pre-post attribute-level differences in condition 3 (the moderately incongruent case) is larger than that in condition 2 (the highly incongruent case).

A total of 230 undergraduate students attending different lectures (namely Marketing Management, Introduction of Management, Fundamental Accounting, and English Literature) in a major university in Taipei participated in our survey ${ }^{7}$. The response rate was $84 \%$ (194 out of 230). Nineteen respondents misunderstood the directions of our survey and therefore were eliminated, leaving a final sample of 175 respondents. For H1 and $\mathrm{H} 2$, an independent sample mean $t$-test (two-tailed and assuming unequal variances) was performed to compare the equality of means of the absolute value of BR. Tables 2 and 3 present the result of $\mathrm{H} 1$ and $\mathrm{H} 2$, respectively. $\mathrm{H} 1$ is supported with respect to all four pairs (at a significance level $p=0.05$ ); $\mathrm{H} 2$ is supported in three of four pairs $(p=$ $0.05)$, and also in pair number 3 , which approaches significance $(p=0.059)$.

\footnotetext{
${ }^{6}$ Before the main survey, we conducted two pre-tests. The first assessed whether durability and style were important attributes of briefcases (9-point scale; $n=49$ ); the second assessed whether the respondents understood how to read the exact counts in each histogram $(n=57)$.

${ }^{7}$ We chose these classes because they were open to all the students across all academic departments.
} 
Table 2. Results for hypothesis H1

\begin{tabular}{ccccc}
\hline \multicolumn{5}{c}{ H1 } \\
\hline Condition & \multicolumn{2}{c}{1} & \multicolumn{2}{c}{3} \\
\hline Sample size & \multicolumn{2}{c}{63} & 3 & 4 \\
\hline Pair & 1 & 2 & -10.797 & -6.838 \\
\hline$t$ value & -7.169 & -11.974 & $0.000^{* *}$ & $0.000^{* *}$ \\
\hline$p$ value & $0.000^{* *}$ & 0.000 & 0.000
\end{tabular}

Note: $* *=$ significant at the 0.05 level (two-tailed).

Table 3. Results for hypothesis H2

\begin{tabular}{ccccc}
\hline \multicolumn{5}{c}{$\mathrm{H} 2$} \\
\hline Condition & \multicolumn{2}{c}{2} & \multicolumn{3}{c}{3} \\
\hline Sample size & \multicolumn{2}{c}{52} & \multicolumn{2}{c}{60} \\
\hline Pair & 1 & 2 & 3 & 4 \\
\hline$t$ value & -6.926 & -2.314 & -1.918 & -4.975 \\
\hline$p$ value & $0.000^{* *}$ & $0.024^{* *}$ & $0.059^{*}$ & $0.000^{* *}$ \\
\hline
\end{tabular}

Note: $* *=$ significant at the 0.05 level, $*=$ significant at the 0.10 level (two-tailed).

The empirical results support our two hypotheses and suggest that a larger degree of BR occurs in the moderately different case (Prop. 3) than in the other two scenarios. Based on our research findings, a "moderately different" brand partner would be the best choice in co-branding partner selection.

\section{Conclusions}

This paper has examined the impact of consumers' Belief Revision (BR) on the cobranding partner selection decision. A comprehensive review of the relevant literature has revealed the lack of explanation for possible failures in the cases of identical and highly incongruent brand pairs. We argue that the positive BR is the main objective for co-branding partners; we have applied two models of stereotype change (namely "book-keeping" and "sub-typing") to show that BR does not occur in the two "extreme" scenarios. Both our theoretical and our empirical findings support the notion that allying with a "moderately different" partner appears to be the best choice.

This research contributes to the co-branding field in three ways. First, to the best of our knowledge, we bridge the corresponding literature gap by explaining why the two "extreme" co-branding cases involve a significant risk. Secondly, we analyze consumer evaluations at the core of attitudinal evaluation - attribute-beliefs. Finally, we show that the mutual transfer of consumers' perceptions about the allying brands can subsequently lead to BR. 
We suggest that branding managers avoid the two "extreme" pairs. This recommendation is valid for firms seeking to form medium- or long-term partnerships. However, this recommendation does not apply to some retail co-branding alliances (e.g., Subway (fast-food restaurant) within Walmart (department store)), because, in these cases, the allying brands have a rather low interdependence. The purchase and consumption of each brand's offerings are largely independent from each other; thus, the concepts of "incongruence" and "congruence" may have only a rather small influence on consumer evaluations.

Of course, this research has a few limitations. First, as already mentioned in Subsection 1.1, the subjectivity of respondents is a major weakness of the CBBE measure, and this weakness may trigger the use of an alternative measure in future studies (e.g., an integrated measure based on BVCC). In doing so, researchers can also include the influences of stakeholders on the co-branding alliance and on each of the partnering brands. For instance, future research could examine the impact of the stakeholders' emotional involvement on brand value to obtain conclusive results. In this case, it might be fruitful to explore how a negative event of the essential role of a stakeholder (e.g., a front-line employee's service failure) changes customers' perceived brand value. The first step in this direction could be an adaption of the magnitude of BR in equation (5) for capturing the respective changes of perceived brand value after the incident. Another way to include the stakeholder influence could be via in-depth interviews with consumers, specifically to investigate how both brands' communities affect each other. Secondly, our model can be further developed into a simulation approach for visualizing the underlying updating process in a dynamic fashion. Consumers' attribute-belief at a specific time point is frequently formed by their previous knowledge of that attribute. By applying this approach, researchers can also observe consumers' learning behavior regarding the attribute-beliefs in various time periods. Finally, future studies may perform an experiment by using psychological measurement scales of personal traits to examine the differences in the BR process between consumers with a book-keeping mindset and those with a sub-typing mindset.

\section{References}

Ahluwalia, R.; Gürhan-Canli, Z. 2000. The effects of extensions on the family brand name: an accessibility-diagnosticity perspective, Journal of Consumer Research 27(3): 371-381. http://dx.doi.org/10.1086/317591

Ambroise, L.; Pantin-Sohier, G.; Valette-Florence, P.; Albert, N. 2014. From endorsement to celebrity co-branding: personality transfer, Journal of Brand Management 21(4): 273-285. http://dx.doi.org/10.1057/bm.2014.7

Bandy, W. D.; Irion, J. M.; Briggler, M. 1998. The effect of static stretch and dynamic range of motion training on the flexibility of the hamstring muscles, Journal of Orthopaedic \& Sports Physical Therapy 27(4): 295-300. http://dx.doi.org/10.2519/jospt.1998.27.4.295

Bass, F. M.; Talarzyk, W. W. 1972. An attitude model for the study of brand preferences, Journal of Marketing Research 9(1): 93-96. http://dx.doi.org/10.2307/3149618

Besharat, A. 2010. How co-branding versus brand extensions drive consumers' evaluations of new products: a brand equity approach, Industrial Marketing Management 39(8): 1240-1249. http://dx.doi.org/10.1016/j.indmarman.2010.02.021 
Besharat, A.; Langan, R. 2014. Towards the formation of consensus in the domain of co-branding: current findings and future priorities, Journal of Brand Management 21(2): 112-132. http://dx.doi.org/10.1057/bm.2013.25

Brodie, R. J.; Glynn, M. S.; Little, V. 2006. The service brand and the service-dominant logic: missing fundamental premise or the need for stronger theory?, Marketing Theory 6(3): 363-379. http://dx.doi.org/10.1177/1470593106066797

Cao, Z.; Sorescu, A. 2013. Wedded bliss or tainted love? Stock market reactions to the introduction of cobranded products, Marketing Science 32(6): 939-959.

http://dx.doi.org/10.1287/mksc.2013.0806

Cummings, J. L.; Holmberg, S. R. 2012. Best-fit alliance partners: the use of critical success factors in a comprehensive partner selection process, Long Range Planning 45(2): 136-159. http://dx.doi.org/10.1016/j.lrp.2012.01.001

Davcik, N. S.; Vinhas da Silva, R.; Hair, J. F. 2015. Towards a unified theory of brand equity: conceptualizations, taxonomy and avenues for future research, Journal of Product and Brand Management 24(1): 3-17. http://dx.doi.org/10.1108/JPBM-06-2014-0639

Desai, K. K.; Keller, K. L. 2002. The effects of ingredient branding strategies on host brand extendibility, Journal of Marketing 66(1): 73-93. http://dx.doi.org/10.1509/jmkg.66.1.73.18450

Fishbein, M.; Ajzen, I. 1975. Belief, attitude, intention, and behavior: an introduction to theory and research. Reading: Addison-Wesley.

Geylani, T.; Inman, J. J.; Hofstede, F. T. 2008. Image reinforcement or impairment: the effects of co-branding on attribute uncertainty, Marketing Science 27(4): 730-744.

http://dx.doi.org/10.1287/mksc.1070.0326

Hadjicharalambous, C. 2006. A typology of brand extensions: positioning cobranding as a subcase of brand extensions, Journal of American Academy of Business 10(1): 372-377.

Hadjicharalambous, C. 2013. A unified framework for evaluating brand alliances and cobranding strategies: implications and future directions, Academy of Marketing Studies Journal 17(2): $13-25$.

Hillyer, C.; Tikoo, S. 1995. Effect of cobranding on consumer product evaluations, Advances in Consumer Research 22(1): 123-127.

James, D. 2005. Guilty through association: brand association transfer to brand alliances, Journal of Consumer Marketing 22(1): 14-24. http://dx.doi.org/10.1108/07363760510576518

Janiszewski, C.; van Osselaer, S. M. J. 2000. A connectionist model of brand associations, Journal of Marketing Research 37(3): 331-350. http://dx.doi.org/10.1509/jmkr.37.3.331.18780

Kalafatis, S. P.; Remizova, N.; Riley, D.; Singh, J. 2012. The differential impact of brand equity on B2B co-branding, Journal of Business \& Industrial Marketing 27(8): 623-634.

http://dx.doi.org/10.1108/08858621211273574

Keller, K. L. 1993. Conceptualizing, measuring, and managing customer-based brand equity, Journal of Marketing 57(1): 1-22. http://dx.doi.org/10.2307/1252054

Keller, K. L. 2007. Strategic brand management: building, measuring, and managing brand equity. 3rd ed. Upper Saddle River: Prentice Hall.

Lanseng, E. J.; Olsen, L. E. 2012. Brand alliances: the role of brand concept consistency, European Journal of Marketing 46(9): 1108-1126. http://dx.doi.org/10.1108/03090561211247874

Lauga, D. O.; Ofek, E. 2011. Product positioning in a two-dimensional vertical differentiation model: the role of quality costs, Marketing Science 30(5): 903-923.

http://dx.doi.org/10.1287/mksc.1110.0652

Lee, C.-L.; Decker, R. 2009. Modeling the effect of belief revisions on the success of co-branding, Journal of Applied Economic Sciences 4(2): 235-253. 
Lee, J. K.; Lee, B. K.; Lee, W. N. 2013. Country-of-origin fit's effect on consumer product evaluation in cross-border strategic brand alliance, Journal of Business Research 66(3): 354-363. http://dx.doi.org/10.1016/j.jbusres.2011.08.016

Leuthesser, L.; Kohli, C.; Suri, R. 2003. 2+2=5? A framework for using co-branding to leverage a brand, Journal of Brand Management 11(1): 35-47.

http://dx.doi.org/10.1057/palgrave.bm.2540146

Lichtenthal, J. D.; Goodwin, S. A. 2006. Product attributes for business markets: implications for selling and sales management, Psychology \& Marketing 23(3): 225-251.

http://dx.doi.org/10.1002/mar.20097

Littlewood, T. J.; Bajetta, E.; Nortier, J. W. R.; Vercammen, E.; Rapoport, B. 2001. Effects of epoetin alfa on hematologic parameters and quality of life in cancer patients receiving nonplatinum chemotherapy: results of a randomized, double-blind, placebo-controlled trial, Journal of Clinical Oncology 19(11): 2865-2874.

Loken, B.; Roedder John, D. 1993. Diluting brand beliefs: when do brand extensions have a negative impact?, Journal of Marketing 57(3): 71-84. http://dx.doi.org/10.2307/1251855

Luo, L.; Chen, X.; Han, J.; Park C. W. 2010. Dilution and enhancement of celebrity brands through sequential movie releases, Journal of Marketing Research 47(6): 1114-1128.

http://dx.doi.org/10.1509/jmkr.47.6.1114

Merz, M. A.; He, Y.; Vargo, S. L. 2009. The evolving brand logic: a service-dominant logic perspective, Journal of the Academy of Marketing Science 37(3): 328-344.

http://dx.doi.org/10.1007/s11747-009-0143-3

Meyers-Levy, J.; Tybout, A. M. 1989. Schema congruity as a basis for product evaluation, Journal of Consumer Research 16(1): 39-54. http://dx.doi.org/10.1086/209192

Miklos-Thal, J. 2012. Linking reputations through umbrella branding, Quantitative Marketing and Economics 10(3): 335-374. http://dx.doi.org/10.1007/s11129-012-9118-7

Moorthy, K. S. 1993. Theoretical modeling in marketing, Journal of Marketing 57(2): 92-106. http://dx.doi.org/10.2307/1252029

Muniz Jr., A. M.; O'Guinn, T. C. 2001. Brand community, Journal of Consumer Research 27(4): 412-432. http://dx.doi.org/10.1086/319618

Na, W. B.; Marshall, R.; Keller, K. L. 1999. Measuring brand power: validating a model for optimizing brand equity, Journal of Product and Brand Management 8(3): 170-184.

http://dx.doi.org/10.1108/10610429910272439

Pappu, R.; Quester, P. G.; Cooksey, R. W. 2005. Consumer-based brand equity: improving the measurement-empirical evidence, Journal of Product and Brand Management 14(3): 143-154. http://dx.doi.org/10.1108/10610420510601012

Park, C. W.; Jun, S. Y.; Shocker, A. D. 1996. Composite branding alliances: an investigation of extension and feedback effects, Journal of Marketing Research 33(4): 453-466.

http://dx.doi.org/10.2307/3152216

Rao, A. R.; Ruekert, R. W. 1994. Brand alliances as signals of product quality, Sloan Management Review 36(2): 87-97.

Sheinin, D. A. 2000. The effects of experience with brand extensions on parent brand knowledge, Journal of Business Research 49(1): 47-55. http://dx.doi.org/10.1016/S0148-2963(98)00116-7

Simonin, B. L.; Ruth, J. A. 1998. Is a company known by the company it keeps? Assessing the spillover effects of brand alliances on consumer brand attitudes, Journal of Marketing Research 35(1): 30-42. http://dx.doi.org/10.2307/3151928

Vaidyanathan, R.; Aggarwal, P. 2000. Strategic brand alliances: implications of ingredient branding for national and private label brands, Journal of Product and Brand Management 9(4): 214-228. http://dx.doi.org/10.1108/10610420010344013 
Van der Lans, R.; van den Bergh, B.; Dieleman E. 2014. Partner selection in brand alliances: an empirical investigation into the drivers of brand fit, Marketing Science 33(4): 551-566.

http://dx.doi.org/10.1287/mksc.2014.0859

Venkatesh, R.; Mahajan, V.; Muller, E. 2000. Dynamic co-marketing alliances: when and why do they succeed or fail?, International Journal of Research in Marketing 17(1): 3-31.

http://dx.doi.org/10.1016/S0167-8116(00)00004-5

Walchli, S. B. 2007. The effects of between-partner congruity on consumer evaluation of cobranded products, Psychology \& Marketing 24(11): 947-974. http://dx.doi.org/10.1002/mar.20191

Washburn, J. H.; Till, B. D.; Priluck, R. 2000. Co-branding: brand equity and trial effects, Journal of Consumer Marketing 17(7): 591-604. http://dx.doi.org/10.1108/07363760010357796

Weber, R.; Crocker, J. 1983. Cognitive processes in the revision of stereotypic beliefs, Journal of Personality and Social Psychology 45(5): 961-977. http://dx.doi.org/10.1037/0022-3514.45.5.961

Winchester, M.; Romaniuk, J. 2008. Negative brand beliefs and brand usage, International Journal of Market Research 50(3): 355-375.

Chia-Lin LEE (Dr) is an assistant professor of marketing in the Department of Business Administration at National Chengchi University, Taiwan. His research interests include co-branding strategy and mathematical modeling. He has successfully received financial support for four research projects from the Taiwan Ministry of Science and Technology during 2010-2016. His research has been published, among others, in European Research Studies Journal.

Reinhold DECKER (Dr) is a full professor of marketing in the Department of Business Administration and Economics at Bielefeld University, Germany. His current research focuses on the modeling of consumer behavior, brand management, the analysis of online consumer reviews and on the internet of things. His research has been published in journals such as Australasian Marketing Journal, Journal of Consumer Behaviour, International Journal of Market Research, International Journal of Research in Marketing, Journal of Marketing Management, Journal of Marketing Research, Journal of MultiCriteria Decision Analysis, and Journal of Product Innovation Management. 